\title{
How People-organization Value-Fit Affects Work Engagement: the Moderation Role of Conscientiousness*
}

\author{
Yu Yan ${ }^{1}$, Jin Zou ${ }^{2}$ and Xiaoyan Zhu ${ }^{3}$ \\ ${ }^{1}$ Department of Psychology, Wuhan University, Wuhan, China \\ ${ }^{2}$ School of Information Management, Central China Normal University, Wuhan, China \\ ${ }^{3}$ School of Economics and Law, Hubei University of Technology, Wuhan, China \\ yanyu@whu.edu.cn, bertha_zj@yahoo.com.cn, uwjudy@gmail.com
}

\begin{abstract}
It has profound effect on the employee performance and organization output. Our research is based on the theoretical and logical reasoning and literature analysis, we conclude that (1) people-organization fit and its dimensions are positively correlated to work engagement; people-organization value-fit and its dimensions have significant predictive effect on work engagement. (2) conscientiousness has significant moderation effect in the relationship of peopleorganization value-fit and work engagement. These concludes not only greatly enriched existing research works in the field of value-fit, but also advanced the exploration of antecedents of work engagement.
\end{abstract}

Index Terms - Person-organization value-fit, work engagement, conscientiousness, personality, moderation

\section{INTRODUCTION}

Work engagement has become a key concept of industrial and organization psychology. It is used to describe the positive emotions and satisfied situations that hiding under the high level work motivation of employees (Bledow et al., 2011) ${ }^{[1]}$. With the development of positive organization behavior theories and deep effect that work engagement has on organization performance and individual perception of happiness, the research focus both in the field of psychology and management has gradually switched from avoidance of job burnout to improve employee's work engagement and generated fruitful research works as a result. (Macey \& Schneider, 2008) ${ }^{[2]}$. The research on antecedent variables of work engagement can be separated into two levels as context factors like job tasks, team support and organization climates etc. and individual characters like demographic variables, attitudinal variables, personality and motivation etc. (Luyckx et al., 2010) ${ }^{[3]}$. But there is little studies about work engagement has been done by the angle of interaction between individual characters and environmental factors (Yu \& Zhu, 2009). So our research has important theoretical significance by viewing this issue through the angle of individual and organization interaction, taking people-organization value-fit as antecedent variable when discussing work engagement. Actually what we do may substantially expand the existing perspectives in the field of organization theory.

The relationship between P-O fit and work engagement is still ambiguous. Based on the job demand-resource model, value-fit makes employees regard themselves as an important part of organization and consequently view job demand as an incentive and challenge and thus maybe put more efforts into work (Crawford, LePine, \& Rich, 2010).From the perspective of self-determinism, it is estimable that value-fit can improve the level of employee engagement by meeting their basic psychological needs. (Greguras \& Diefendorff, 2009).Some researchers also claim that high work requirements and high work challenge is attractive to those employees who are already highly involved in their work and can further promote their work input level; At the same time, the mismatch of needs and reality can better inspire the potential motivation of employees and result in higher level of work engagement (Warr \& Inceoglu, 2012). In this study, the local Chinese employees were taken as our object to explore the effect that people-organization value-fit has on work engagement. It is not only an expansion of work requirement-resources model and self-determinism theory, but also a further clarification and test of the relationship between people-organization values fit.

Meanwhile, a study of related research about conscientious shows that (Renn et al., 2011) since conscientiousness has strong predictive power, it is often used as a moderator in the quantitative research in the field of psychology and organization behavior and shows significant effect (Inceoglu \& Warr, 2011) ${ }^{[4]}$. While enormous research on exploring the relationship between people-organization fit and its outcome variables, or work engagement and related variables also called for adding personality factors as moderators (Warr \& Inceoglu, 2012) ${ }^{[5]}$. So based on above literature review, this study hope to explore how conscientiousness functions in the mechanism that peopleorganization fit affects work engagement with respect to expand and advance previous related research.

\section{THEORETICAL OVERVIEW}

A. Conceptual framework of people-organization value-fit

Research for fit was firstly originated from interactive psychology. Chatman (1989) put forward a very well-known people-organization fit model. It takes both individual and organizational factors into consideration and highlights the interactive effects of these factors. Greguras et al hold that target congruency can play the key role in determination of individual and organization fit (Greguras \& Diefendorff, $2009)^{[6]}$. Some other researchers think individual and 
organization climate fit should be considered an important aspect of congruency fit theory (Ambrose, Arnaud, \& Schminke, 2008) $)^{[7]}$.

Complementary fit also exists in the concept of peopleorganization fit as a totally different fit type with congruency fit(Kristof-Brown, 2007) ${ }^{[8]}$. Empirical studies prove that subjective people-organization fit comes from not only the individual perception of employee and organization likelihood, but also refrained by their perception of needs supplement between individual and organization in a greater degree (Park, Monnot, Jacob, \& Wagner, 2011) ${ }^{[9]}$.

But Ryan found that values is more stable than objects and more influential on individual behavior in his comparison study of values fit and objects fit (Ryan \& Kristof, 2003) ${ }^{[1]}$. Hoffman prove that the evaluation of consistency degree between individual value and organization value is the most common way to measure people-organization fit by metaanalysi (Hoffman \& Woehr, 2006) ${ }^{[11]}$. Presently the most frequently cited definition of value-fit by scholars in practice is the consistency degree between the desired values of an individual employee and his or her perception of organization values (Edwards \& Cable, 2009) ${ }^{[12]}$.

\section{B. concept of work engagement}

Kahn was the pioneer who explained work engagement systematically (Kahn, 1990) ${ }^{[1]}$. Leiter ( 2001 ) et al regard work engagement and job burnout as two continuous ends which include energy, involvement and performance. Work engagement is on the positive side while job burnout is totally opposite to work engagement(Leiter et al., 2001) ${ }^{[14]}$.

However , Schaufeli et al ( 2012 ) think that work engagement and job burnout are not necessarily two extremely opposite, they are just two psychological states that are linked to each other but independent at the same time ${ }^{[15]}$. Sonnentag ( 2010 ) thinks that although the attitude level of work engagement are overlap in some way with job satisfaction and organizational commitment, but it still has its uniqueness and value in the energy level and involvement level.

Crawford ( 2010 ) studied work engagement and job burnout under the theoretical framework of job demandresource model $^{[1]}$. Results from their meta-analysis shows that work engagement is positively correlated to work resources. Schaufeili ( 2012 ) summarized studies of work engagement in the 30th International Conference on Occupational Health. Our research cites the definition of Schaufeli as an emotional motivation with which an individual is full of energy, vigor and involvement in work and is willing to dedicate his or her own resources for the organization.

\section{C. concept of conscientiousness}

Conscientiousness represents the serious and responsible attitudes that an individual has toward work and life. Individual with high level of conscientiousness is more responsible, with higher achievement motivation and perseverance, well organized and tend to pursuit for excellence. Individual with high degree of conscientiousness usually exhibit a more proactive attitude to solve difficulties with effective strategies when confronting problems and potential conflicts (Witt et al., 2002).

Conscientiousness is an important dimension in the Big Five personality. The conscientiousness subscale of simplified Big Five Questionnaire is widely and frequently used in empirical research (Greenbaum, Mawritz, \& Eissa, 2012) ${ }^{[1]}$. Demerouti ( 2006 ) adopt the conscientiousness subscale in his study of the moderation effect of conscientiousness personality among work characteristics, peak experience and performance $^{[2]}$. Other empirical studies done in recent years also adopt this scale and proved it to having good reliability and validity (Halbesleben, et al., 2009) ${ }^{[3]}$.

\section{RELATED STUDIES ON WORK ENGAGEMENT}

\section{A. people-organization value-fit and work engagement}

People-organization fit reflects the degree of consistency between individual values and organization values that perceived by employees. Organization value system will affect demands that an organization has on its employees and resources that it can provide (Hoffman, et al., 2011). Similarly, the values held by employees will affect their expectations of organization and how they view organization demand. Therefore, according to job demand -resource model, when the level of people-organization value-fit is low, employees are more tend to have a negative interpretation of job demand and organization behaviors, regard job demand as an obstacle and source of pressure and result in low level of work engagement. When the level of people -organization value-fit perceived by employees is high, they are more tend to view themselves as an important force in the organization and work toward similar goals with the organization, and therefore result in more involvement into work.

However, in recent years, there a few studies put forward different opinions when comparing job satisfaction and work engagement. Warr ( 2012 ) found in their empirical research that poor fit between needs and reality will result in low level of job satisfaction and high level of work engagement. They further explained that job satisfaction is a passive response to the external environment. Only when the fit level of needreality is high, job satisfaction will be formed; while work engagement is the potential motivation state of individual, need-reality misfit is more tend to inspire individual's work motivation and result in high work engagement. They believe that high job demand and high job challenge is more attractive to those who have high level of work engagement and may further promote their level of work engagement (Warr \& Inceoglu, 2012). From above theoretical and logical reasoning and empirical analysis, the relationship between peopleorganization value-fit and work engagement, we put forward the first Proposition:

Proposition 1 : People-organization fit and its dimensions are positively correlated to work engagement; peopleorganization value-fit and its dimensions have significant predictive effect on work engagement. 


\section{B. The effect of conscientiousness in the relationship between} people-organization fit and work engagement

Kristof ( 1996 ) proposed that personality differences may affect the degree of attention that an individual put into people-organization fit when seeking and choosing organizations. A large number of empirical studies have shown that that the level of conscientiousness will affect an individual's work attitude and behaviors (Demerouti, 2006). Inceoglue \& Warr ( 2011 ) explored the impact of the Big Five personality factors on work engagement. They found that only conscientiousness and emotional stability can be used as independent predictor of work engagement (Inceoglu \& Warr, 2011).

Hirschfeld \& Thomas (2008) thinks that initiative personality can better able to promote individual work engagement because these qualities are abilities that an individual has to effectively control their own thoughts and emotions, which enable him to interact better with surrounding environment. McFerran ( 2010 ) found that employees with high level of conscientiousness are more likely to follow ethical principles and fulfill their own duties ${ }^{[20]}$. Renn et al

(2011) show that individuals of low conscientiousness tend to delay the completion date of work task and display poor self-discipline. According to above literature review about conscientious, we assume that ${ }^{[21]}$ :

Proposition 2 : Conscientiousness has significant moderation effect in the relationship of people-organization value-fit and work engagement.

\section{RESEARCH DIRECTIONS}

\section{A. Theoretical and managerial implications}

This study proved the positive effect that $\mathrm{P}-\mathrm{O}$ value-fit has on work engagement which is a good response and improvement to current academic debate on the relationship between fit and work engagement. Work demand-resource model and self-determination theory both potentially imply that fit has positive effects on work engagement, while latest empirical research concluded that unfit can arouse the potential motivation of an individual and therefore promote work engagement. This research not only found that there exists significant positive correlation effect between POF and work engagement, but also further explored there are two dimensions of P-O value-fit that are strong predictors of work engagement. This conclusion has important theoretical values in the expansion and improvement of work demand-resource model and enhancing the explaining power of selfdetermination theory. This study is based on an important psychological view that behavior is an interactive function between individual and context. Two variables, P-O value-fit and work engagement, were put together in one model in this study, which not only greatly enriched existing research works in the field of value-fit, but also advanced the exploration of antecedents of work engagement.

Conclusions of this study show that P-O Value-fit is a strong predictor of work engagement. Therefore, companies should attract and attain talents whose personal values are nicely fitted with organization values through recruitment to improve the whole organization work engagement level. This study also found that employee and team orientation dimension of P-O Value-fit is the strongest predictor of work engagement. Thus a satisfied psychological contract can be formed through an initiative interaction between employees and organization. The unfit problems of individual and organization values can be solved consequently.

\section{B. Limitation and future research}

Firstly, this study focuses on subjective perception of fit, namely, the evaluation of fit comes from employees' subjective feeling of personal expected values and organization values. This evaluation method would affected by bias of employees that they have on organizations they are working for. Therefore, future research may use object evaluation on actual organization values to more effectively measure $\mathrm{P}-\mathrm{O}$ value-fit.

Secondly, there were limited factors extracted from factor analysis, we finally adopt single-dimension analysis with work engagement. Future research may conduct multi-dimension analysis to explore the relationship between each dimension of $\mathrm{P}-\mathrm{O}$ value-fit and different dimensions of work engagement.

Thirdly, this study only explored the relationship between $\mathrm{P}-\mathrm{O}$ value-fit and work engagement, future study still may introduce more work related attitude and behavior variables, such as emotional stability, working conditions, autonomy etc. Or may combine P-O value-fit with other types of fit, such as people-job fit, people-team fit, subordinate -superior fit and so on to better explore the value that P-O value-fit has on work engagement.

\section{References}

[1] Bledow, R., Schmitt, A., Frese, M., \& Kühnel, J. (2011). The affective shift model of work engagement. Journal of Applied Psychology, 96(6), 1246.

[2] Macey, W. H., \& Schneider, B. (2008). The meaning of employee engagement. Industrial and Organizational Psychology, 1(1), 3-30.

[3] Luyckx, K., Duriez, B., Klimstra, T. A., \& De Witte, H. (2010). Identity statuses in young adult employees: Prospective relations with work engagement and burnout. Journal of Vocational Behavior, 77(3), 339349.

[4] Inceoglu, I., \& Warr, P. (2011). Personality and work engagement. Journal of Personnel Psychology, 10(4), 177-181.

[5] Warr, P., \& Inceoglu, I. (2012). Work engagement, job satisfaction, and contrasting associations with person-job fit.

[6] Greguras, G. J., \& Diefendorff, J. M. (2009). Different fits satisfy different needs: Linking person-environment fit to employee commitment and performance using self-determination theory. Journal of Applied Psychology, 94(2), 465.

[7] Ambrose, M. L., Arnaud, A., \& Schminke, M. (2008). Individual moral development and ethical climate: The influence of person? $\square$ organization fit on job attitudes. Journal of Business Ethics, 77(3), 323-333.

[8] L.Kristof-Brown, A. (Ed.). (2007). Issues of person-organization fit. US: Lawrence Erlbaum Associates Publishers.

[9] Park, H. I., Monnot, M. J., Jacob, A. C., \& Wagner, S. H. (2011). Moderators of the relationship between person-job fit and subjective well-being among Asian employees. International Journal of Stress Management, 18(1), 67.

[10] Ryan, A. M., \& Kristof-Brown, A. (2003). Focusing on personality in person-organization fit research. MR Barrick \& AM Ryan, Personality and work, 262-288. 
[11] Hoffman, B. J., Bynum, B. H., Piccolo, R. F., \& Sutton, A. W. (2011). Person-Organization Value Congruence: How Transformational Leaders Influence Work Group Effectiveness. The Academy of Management Journal (AMJ), 54(4), 779-796.

[12] Edwards, J. R., \& Cable, D. M. (2009). The value of value congruence. Journal of Applied Psychology, 94(3), 654.

[13] Kahn, W. A. (1990). Psychological conditions of personal engagement and disengagement at work. Academy of management journal, 692-724.

[14] Leiter, M., Maslach, C., \& Schaufeli, W. (2001). Job burnout. Annual Psychological Review, 52, 397-422.

[15]Schaufeli, W. (2012). Work engagement: An emerging psychological concept.

[16]Crawford, E. R., LePine, J. A., \& Rich, B. L. (2010). Linking job demands and resources to employee engagement and burnout: A theoretical extension and meta-analytic test. Journal of Applied Psychology, 95(5), 834.

[17]Greenbaum, R. L., Mawritz, M. B., \& Eissa, G. (2012), Bottom-line mentality as an antecedent of social undermining and the moderating roles of core self-evaluations and conscientiousness. The Journal of applied psychology, 97 ( 2 ): 343-59.

[18]Demerouti, E. (2006). Job characteristics, flow, and performance: The moderating role of conscientiousness. Journal of Occupational Health Psychology, 11(3), 266.

[19]Halbesleben, J. R. B., Harvey, J., \& Bolino, M. C. (2009). Too engaged? A conservation of resources view of the relationship between work engagement and work interference with family. Journal of Applied Psychology, 94(6), 1452.

[20]McFerran, B., Aquino, K., \& Duffy, M. (2010). How personality and moral identity relate to individuals' ethical ideology. Business Ethics Quarterly, 20(1), 35-56.

[21]Renn, R. W., Allen, D. G., \& Huning, T. M. (2011). Empirical examination of the individual? level personality? $\square$ based theory of self? $\square$ management failure. Journal of Organizational Behavior, 32(1), 25-43. 